\title{
Documentos sobre aniversarios, reparticiones y capellanes
}

\author{
José LUIS MARTIN ROdRíguez *
}

En el Cómpoto o Arte de contar del cabildo segoviano ${ }^{1}$ se habla de la mayordomía de Reparticiones que administra los bienes dejados para la celebración de aniversarios por el alma de los benefactores de la iglesia, y es de suponer que el volumen alcanzado por este tipo de donaciones llevaría a los demás cabildos peninsulares a individualizar estas rentas y a incluir en los libros de Obituarios o Aniversarios las obligaciones contraías por el cabildo, es decir por las dignidades o personas, canónigos y racioneros, que forman el cabildo en sentido estricto, y por los auxiliares de éstos: capellanes, sochantre, mozos de coro, organista, portero, campanero, refitolero, barrendero, perrero... sobre cuyas obligaciones y situación estamos mal informados.

Dentro de estos auxiliares destacan con personalidad propia los capellanes que, en algunos casos, llegan a organizarse en cofradías como la existente en Segovia, al menos, desde comienzos del siglo $\mathrm{xv}^{2}$. Celebrar las fiestas con una misa cantada y recordar a los difuntos que con sus donativos buscaron la salvación del alma e hicieron posible la prosperidad de la catedral y de los propios capellanes son la principal obligación de éstos, a los que se exige, además, asistir a la extremaunción

* UNED. Dpto. de $\mathrm{H}_{.}{ }^{2}$ Medieval, $\mathrm{H}_{.}{ }^{a}$ Moderna y Ciencias Historiográficas.

1 Un resumen de este manual de contabilidad y distribución interna de las rentas del cabildo aparecerá en el «Homenaje al Profesor Marcelo Vigil» que actualmente prepara la Universidad de Salamanca.

2 Publico los Estatutos de esta cofradía en el "Homenaje al Profesor Emilio Sáez» que preparan el Consejo Superior de Investigaciones Científicas y la Universidad de Barcelona. 
de los fieles, tomar parte en los funerales y decir los responsos correspondientes.

La forma de celebrar los aniversarios depende de la voluntad del benefactor y del dinero que destine para que se celebre su memoria. Entre los numerosos documentos o anotaciones de los libros de Aniversarios que podrian citarse he elegido un texto conservado en el archivo capitular de Zamora en el que se recoge la donación hecha por el canónigo Juan Alfonso a la mesa de los capellanes o mesa del cabildo menor para que, a cambio de esta ayuda material, los capellanes le efiziesen alguna ayuda e limosna de spiritual" ${ }^{3}$.

La donación es en principio un acuerdo entre Juan Alfonso y los capellanes pero para que tenga validez ha de ser confirmada oficial $y$ solemnemente por el obispo y los canónigos, reunidos en cabildo extraordinario en la capilla de Santiago. De las palabras de Juan Alfonso se deduce, sin lugar a dudas, que también en Zamora los capellanes tienen mesa o administración separada y que sus ingresos son relativamente escasos: "los capellanes trabajan mucho... e de las rentas de la dicha su mesa non han mantenimiento convenible", hecho que mueve al canónigo a hacer entrega de 8.000 maravedís para que con ellos compren bienes cuyas rentas servirán para incrementar los ingresos de los capellanes y ayudar a la reparación de algunas de sus posesiones.

Con este dinero, los capellanes compran una casa con su bodega en la calle de Balborraz y, en justa correspondencia hacia Juan Alfonso, se comprometen, por sí y sus sucesores, a decir una misa cantada de la Virgen cada sábado y otra en las cinco festividades de Santa María ${ }^{4}$. Las misas se dirán en la capilla de Santa María Magdalena, donde Juan Alfonso ha elegido sepuitura, «en el suelo, iunta al pie del dicho altar». El día de la santa titular de la capilla se dirá otra misa en el mismo altar, y si hubiera entredicho en la catedral se rezarían las misas en lugar de cantarlas. Tras las mismas se reza un responso u oración que, lógicamente, varía según que Juan Alfonso esté vivo o haya fallecido.

Por la asistencia a las misas y a las vísperas que se rezan el día anterior, cada capellán recibe nueve maravedís que pierden, así como las

Documentos del 21 de junio de 1438 (ACZ, E, 2, 38).

4 Son las fiestas de la Natividad, Purificación, Asunción, Anunciación y la fiesta de la Virgen que se celebra en diciembre, "que dizen Santa María de la O". 
rentas, si dejan de cumplir con sus obligaciones durante un mes seguido; en este caso, las rentas serían entregadas al deán y cabildo que asumirían, lógicamente, las obligaciones de misas y vísperas.

Al frente de los capellanes hay en todas las catedrales un mayordomo o capellán mayor cuyas obligaciones recoge un documento abulense del 2 de agosto de $1504^{5}$ por el que se actualizan las multas que debe pagar el capellán: Las penas habían sido fijadas mucho antes, en moneda antigua, cuando las rentas de los capellanes eran escasas y el nombramiento de capellán mayor era revocable por el obispo y cabildo; con el tiempo, las multas han perdido valor y, además, el nombramiento se ha hecho fijo por lo que la pena no es "condigna ni bastante» $y$, por otro lado, el capellán mayor ha ascendido de categoría dentro del cabildo: de racionero ha pasado a ser considerado dignidad, y en el mismo documento se le obligará a renunciar a esta situación al tiempo que se le fuerza a aceptar penas pecuniarias actualizadas así como la posibilidad de ser depuesto.

Como es sabido, el capellán está obligado a administrar los sacramentos a los feligreses, parroquianos y beneficiados de la catedral y entre sus deberes se incluye acompañar, con los demás capellanes, los cuerpos de quienes desean ser enterrados en la iglesia catedral; responsabilidad suya es asistir al coro durante el rezo de las horas y en las misas de la Virgen y de los fallecidos o de aniversarios, leer las capítulas $y$ oraciones, echar perdones y bendiciones, hacer las aspersiones de agua bendita en el coro; decir misa al alba, incensar el altar mayor los días de fiestas, y renovar el Santísimo cada quince días.

Administrar los sacramentos es una obligación no remunerada, al menos no de forma directa como ocurre con la asistencia a maitines, prima... por la que se recibe una determinada cantidad de dinero, y lo mismo puede decirse de acompañar a los muertos: es una obligación por la que los capellanes cobran, de la misma forma que perciben una cantidad los miembros del cabildo y sus auxiliares: mozos de coro, pertiguero, campanero... Cuando en Avila fallece «algún cavallero o dueño de estado" y sus herederos quieren que el cabildo con sus capellanes, sacristanes y mozos de coro vayan a honrar al difunto y acompañen su

5 Se conserva en el AHN., Códices, 914 b, fols. 22 r. 23 r. 
cuerpo a la iglesia o monasterio elegido para su sepultura, el deán y cabildo reciben "por la dicha vigilia e processión» mil quinientos maravedís ${ }^{6}$ y otros tantos por la misa del día siguiente; de esta cantidad, corresponden a los capellanes doscientos maravedís ${ }^{7}$, diez a cada uno de los sacristanes y otros tantos al pertiguero y al campanero.

Ni siquiera ante la muerte son iguales los hombres: ser miembro del cabildo (dignidad, canónigo racionero o medio racionero) lleva consigo unas condiciones especiales. Cuando muere un beneficiado del cabildo todos los demás están obligados a «yr procesionalmente con su cruz e cirios e capellanes e sacristanes por el tal cuerpo a su casa» desde la que el cadáver es llevado en procesión a la catedral por los iguales del fallecido, por personas "que fueron de aquella mesma calidad que es el tan deunto"; en la iglesia se le dicen tres lecciones y una misa solemne de requiem, y, por todo, recibe el cabildo mil doscientos maravedís de los que da doscientos a los capellanes, dos reales de plata a los sacristanes «porque tengan carga de fazer la cama y estrado donde ha de ser colocado el tal cuerpo', dos maravedís a cada mozo de coro, diez maravedís al pertiguero, y al campanero según el trabajo que realice: si ha de tañer todas las campanas ciento veinte maravedís; si no tañe la campana mayor, ochenta maravedís, y si sólo toca dos esquilones sesenta maravedís.

Evidentemente, los documentos reproducidos y las breves notas incluidas en esta presentación no agotan el tema; son sólo una mínima parte del abundante material que custodian nuestros archivos sobre dos temas poco conocidos: la actuación de los auxiliares de los cabildos catedralicios y la actitud ante la muerte, que siguen esperando al historiador que los rescate del olvido.

- Puede verse el texto en los fols. $10 \mathrm{r}$. $11 \mathrm{r}$. Una mano posterior ha tachado la cantidad y ha escrito 8.000 .

7500 en letra posterior. En los folios 8 r. 9 r. pueden verse «los maravedis que los señores e capellanes e moços de coro ganan a las horas ansí a matines como a las horas del día e en qué tienpo", $y$ en los folios $11 \mathrm{r}$. $12 \mathrm{r}$. se recogen las "Pitanças que los capellanes ganan por año"... 


\title{
APÉNDICE DOCUMENTAL
}

\author{
DOCUMENTO 1
}

\section{DONACIÓN DEL CANÓNIGO JUAN ALFONSO}

En la noble çibdat de Çamora. sábbado veynte e un días del mes de junio, año del nasçimiento de nuestro señor Ihesu Christo de mill e quatroçientos e treynta e ocho años.

En presençia de mí el notario e testigo de yuso escriptos, este día, saliendo de missa de prima, estando el nuevo reverendo in Christo padre e señor don Pedro, por la gracia de Dios e de la sancta eglesia de Roma obispo de la dicha çibdat de Çamora e del consejo de nuestro señor el rey, dentro en la capiella de Sanctiago que es en la claostra de la eglesia cathedral de Sant Salvador de la dicha çibdat de Çamora donde los señores deán a cabillo della acostunbran tener e fazer sus cabillos, assentado en unas gradas de madera que están en la dicha capilla, e estando assimesmo con él dentro en el dicho cabillo los honrrados e discretos varones don Ferrand Fernandes, maestrescuela de la dicha eglesia, e lohan Sanches de Balbás, bachiller en decretos, thesorero de la eglesia de Avila, e Diego de Campo, logarteniente de deán, e Pero Fernandes de Toro, abbat de Sancta María la Nueva, e Alvar Fernandes, e Pero Fernandes de Puerta, abbat de Sancti Spiritus, e Ruy Díaz, abbat de Sant Frontes, e Fernand Gómez e Alvar López e Pero Gonçalez de Carrión, canónigos en la dicha eglesia cathedral de Çamora, paresçieron ý presentes delante el dicho señor obispo de la una parte Iohan Alfonso de Çamora, canónigo en la dicha eglesia cathedral de Çamora e canónigo de León, e de la otra parte Fernando Gonçalez de Toro e Iohan 
Rodríguez, subchantre, e Alfonso Pérez e lohan Martínez de Sant Estevan e Alfonso Fernandes del Coro e Fernand Gonçalez de Bonilla, capellanes perpetuos de la dicha eglesia cathedral de Çamora, que son más de las dos partes de los doze capellanes perpetuos del número e cabildo menor de la dicha eglesia cathedral de Çamora.

E luego el dicho lohan Alfonso, canónigo, propuso antel dicho señor obispo e dixo que porque la mesa de los dichos capellanes, que se llama la mesa del cabillo menor de la dicha eglesia cathedral, es pobre e de pequeñas rentas e los capellanes della trabajan mucho e continuan en el serviçio de Dios e de la dicha eglesia, e de las rentas de la dicha su mesa non han mantenimiento convenible, por ende, que por serviçio de Dios e acresçentamiento del culto divinal en la dicha eglesia e queriendo acresçentar el mantenimiento de los dichos capellanes e por remedio de su anima e desencargo de su conçiençia de algunos cargos que tenía en esta vida e por remedio e remissión de sus peccados e por otras iustas e piadosas causas que lo a ello movían, que avía propuesto e acordado e deliberado de doctar las dichas capellanías e mesa menor de ocho mill maravedís desta moneda usual para que dellos conpren los dichos capellanes algunas possessiones e bienes que riendan perpetuamente para las dichas capellanías e mesa menor e para los capellanes que son e fueren perpetuamente de la dicha eglesia e para ayuda de reparar algunas possessiones de la dicha mesa e capellanías que han menester reparaçión, porque sus rentas sean acresçentadas.

Otrossí, dixo e propuso ante el dicho señor obispo que porque lo sobredicho quedasse en memoria e otras buenas personas se moviessen con sanctas e buenas entençiones a procurar e fazer lo semejante, que cessante toda pactión e convención illícita e desonesta e reprobada, que él avía rogado e rogava a los sobredichos capellanes perpetuos que en recompenssacçión de lo sobredicho temporal le fiziessen alguna ayuda e limosna de spiritual en memoria perpetua de lo suso dicho.

A lo qual ellos le avian respondido e respondían que les plazía e eran contentos en esta manera, que ellos que se davan e dieron e ovieron por contentos, entregos e pagados de los dichos ocho mil maravedís que el dicho loahan Alfonso los avía dado e pagado e de que avía doctado, doctava e doctó las dichas capellanías e mesa del dicho cabilldo menor.

Los quales dichos ocho mil maravedís desta dicha moneda usual confessaron en juyzio e delante del dicho señor obispo, exclusa toda 
excepçión, que resçibian e resçibieron del dicho lohan Alfonso, canónigo, en nombre de las dichas capellanías e para ellas e para comprar e reparar possessiones que rindiessen para ellas e para fazer los encargos de yuso escriptos, de que se dieron por contentos e pagados a todas sus voluntades. $E$ renunçiaron expresamente todas leyes e derechos que en esta parte e contra lo suso dicho les podrían aprovechar e ayudar.

E que la offresçían e offrescieron e prometieron delante del dicho señor obispo firmemente e por sollempne stipulaçión e por sí e por sus successores en las dichas capellanías de fazer e complir perpetuamente lo que se sigue: convién a saber, que sin excepçión, dilaçión e sin escusa alguna farán dezir e dirán e cantarán perpetuamente para siempre iamás una missa cantada de la Virgen gloriosa nuestra madre Sancta María cada sábbado, del officio que ocurriere segund el tiempo; e que la dirá uno de los dichos capellanes que son e fuere; e que la dira en la capiella de Sancta María Magdalena, al su altar, que es en la claostra de la dicha eglesia cathedral, donde el dicho lohan Alfonso, canónigo tien elegida e señalada su sepultura en el suelo, iunta al pie del dicho altar.

Otrossí, que dirán más en cada año e perpetuamente para siempre en la dicha capilla e altar de la Magdalena çinco missas cantadas a honor e reverençia de la dicha Virgen María, cada missa en cada una de las sus çinco fiestas, en el día en que vinier cada año cada fiesta, que son: la Natividat e la Purificaçión e la Assumpción e las otras dos fiestas suyas de la Anunçiaçión que son la una en el mes de março e la otra en el mes de deziembre, que dizen Sancta María de la O.

Otrossí, que dirán más en la dicha capilla de la Magdalena e al su altar otra missa de la dicha señora sancta María Magdalena, cantada, en cada un año e perpetuamente en el día que viniere su fiesta e con sus viésperas cantadas el día antes e ante el dicho altar. E que se digan acabando los señores deán e cabillo de la dicha eglesia de dezir la nona en su coro. E si el día de la Magdalena venier en sábbado, que aquel día nos se diga otra missa de sancta María de las suso nombradas salvo tan solamente la de la dicha señora Magdalena.

Empero, si por aventura acaesçiere que en qualquier de los días suso nombrados en que se deven e han a dezir las dichas missas cantadas en la dicha capilla de sancta María Magdalena estovier entredicho puesto en la dicha eglesia cathedral, que entonce la tal missa o missas que se avían de dezir cantadas non se digan, salvo rezadas en quanto durar el tal entredicho. 
Otrossý, si por aventura alguna vegada acaesçiere en la dicha capilla algún impedimento legítimo e tal que por él se deva dexar de dezir misma alguna de las suso dichas en los dicho días del sábbado e en las otras fiestas sus nombradas, que las dexen de dezir en quanto durar el tal impedimento, el qual cessante que tornen luego los dichos capellanes a dezir en la dicha capilla las missas cantadas que por el tal impedimento fallesçieron de se dezir.

Otrossý, que acabada de se dezir cada missa, que el prestre que la dixiere, vestido con sus vestimentas bendichas, ante que se despoje, e los capellanes que fueren presentes, que sean tenudos de dezir e digan un responso a media voz por el dicho lohan Alfonso, canónigo, sobre su sepultura. E entretanto que fuere vivo que digan la oración "Omnipotens sempiterne Deus miserere famulo tuo lohani et dirige eum secundum tuam clementiam" etcétera. E después de su finamiento que digan la oración «Da nobis, Domine, ut animam famuli tui sacerdotis» etcétera. E en fin de cada responso "Fidelium Deus", sacando e teniendo en vida del dicho lohan Alfonso, canónigo, e después della, la cruz sobre su sepultura e esparziendo ý en la fin de cada missa e viésperas la agua bendicha.

Item, que los capellanes del dicho número que fueren presentes en la dicha çibdat e vinieren a la dicha eglesia, que sean tenudos de estar a las dichas missas e viésperas e offiçiarlas e poner los ornamentos e libros e todas las otras cosas que fueren menester para ello. E los que lo anssí non fizieren nin vinieren a las missas antes que se acaben los kyrios e a las viésperas antes que se acabe el primero psalmo, non aviendo legítima escusación e non estovieren a todo ello fasta que se acabe, que non ayan parte de los maravedís que se dieren e repartieren para lo suso dicho, que son nueve maravedís a cada missa e otros nueve maravedís a las dichas viésperas.

E que estas missas que se digan en tanto que andodiere o diviere andar la campana e aguijón de prima porque por causa dello non se escusen los capellanes de entrar en el coro e continuar en él sus horas.

E que los dichos nueve maravedís que sean para los capellanes que fueren a todos presentes.

E el dicho lohan Alfonso, canónigo, en su vida que dé las candelas que él entendiere que cumplen para las dichas missas e viésperas; e después de su vida que las den e pongan los dichos capellanes de su mesa. 
E los dichos capellanes dixieron que confessavan e confessaron libremente que de los dichos maravedís que el dicho lohan Alfonso, canónigo les avía dado e entregado e de que avía doctado las dichas capellanías e mesa, que avían comprado e pagado para ella e para que riendan perpetuamente para los dichos encargos e cosas suso dichas unas casas con su bodega, que son en esta dicha çibdat a la calle que dizen Balborraz, que fueron de María Fernández, ya defuncta, muger que fue de Pero García, retallador, que han por linderos de la una parte casas que fueron de Martýn Fernández del Acetre e de la otra parte casas de la capellanía de Sancto Antón que es edifficada en la eglesia de Sancta Eulalia desta çibdat; e por quantía de ocho mil maravedís. Las quales subrrogavan e subrrogaron en logar de los dichos maravedís e doctación fecha por el dicho Iohan Alfonso, canónigo.

E el dicho lohan Alfonso, canónigo, dixo que acceptava e acceptó los dichos encargos e limosna que los sobredichos les offresçían e le plazía e plogo dello.

E pidió al dicho señor obispo que diesse su liçençia devidamente a él e a los dichos capellanes para fazer e otorgar lo suso dicho e los condempnasse a todo ello e a sus subcessores e interpusiesse a todo ello su decreto e auctoridat en manera que valiesse e fuesse firme e perpetuo para siempre.

E los dichos capellanes assý ge lo pidieron e supplicaron por sý e en nombre de las dichas sus capellanías e mesa e cabilldo menor; e imploravan e imploraron su offiçio en lo que complía.

E luego, el dicho señor obispo ovo su devida enformaçión e dixo que porque fallava lo sobre dicho ser todo a serviçio de nuestro señor Dios e bien de la ánima del dicho lohan Alfonso, canónigo, e provecho de los dichos capellanes e de su mesa e por otras justas causas que lo a ello movieron, que dava e dio liçençia en la meior manera e forma que podía e devía al dicho lohan Alfonso, canónigo, para fazer la dicha doctaçión e a los dichos capellanes para la rescebir e offresçer los dichos encargos e se obligar por sí e por sus suçessores e para poner sobre sý e sobre los bienes de la dicha mesa pena para lo assý fazer e complir perpetuamente. E que mandava e mandó, de consentimiento de amas las dichas partes, a los dichos capellanes e a los que después dellos succediessen en las dichas capellanías que toviessen e compliessen e fiziessen todos los dichos encargos e guardassen todo lo contenido en este contracto so pena que por cada vegada que fallesçiessen de complir todos los encar- 
gos e cada cosa dello e por cada cosa que fallesçiessen, que incurriessen en pena de diez maravedís para los presos de la cárçel de concejo desta dicha çibdat. $E$ si por un mes continuo lo fallesçiessen, que perdiessen por esse mesmo fecho toda la dicha doctaçión e se tornasse e applicasse al deán e cabilldo de la dicha eglesia e su mesa capitular; e las possessiones que de los dichos maravedis comprasen e las que para ello obligassen; e que los dichos deán e cabilldo fuesen tenudos a fazer los dichos encargos.

Sobre lo qual dixo que encargava e encargó sus conçiençias e que a consentimiento de amas las dichas partes assý lo iuzgava e iuzgó, condempnava e mandava e pronunció por su sentençia deffinitiva e interpuso a ello todo su decreto e auctoridat en unos escriptos que en las manos tenía para que valiesse e fuesse firme e perpetuo para siempre iamás.

E los dichos lohan Alfonso, canónigo, e capellanes dixieron que assý lo acceptavan e acceptaron, resçibieron, consintieron e approvaron.

E luego los dichos capellanes con la dicha liçençia obligaron expressamente a ssý e a sus successores e los bienes de la dicha su mesa, señaladamente las dichas casas e bodega que compraron de los dichos maravedís, e más otras casas suyas con su bodega e cubas en que agora mora de su mano e plazentimiento lohan Sánchez de Orgaz, notario apostolical, que son en la dicha çibdat en par de la eglesia que dizen Sant Martýn el Pequeñino, que está çerca la dicha eglesia cathedral, que han por linderos de amas partes casas de la dicha eglesia de Sant Martýn, de complir e fazer los dichos encargos perpetuamente e so las dichas penas solemnemente stipuladas.

E nós, los dichos capellanes, pedimos e supplicamos e damos poder complido al dicho nuestro señor don Pedro, obispo desta dicha çibdat e obispado, e a los sus successores que después de su merçed vinieren, e a los sus provisores, vicarios de la sancta madre eglesia que para ello fueren requeridos, so cuyas jurisdiciones nos sometemos de nuestras çiertas scientias e sabidurias spontáneas e libres voluntades syn error e syn dolo e syn engaño alguno, renunçiando expressamente toda excepçión e declinatoria de jurisdiçión e fuero e la ley «Si convenerit», que fabla en esta materia, que para ello fuere o fueren requerido o requeridos que nos fagan atener e complir esta dicha sentençia e decreto e todo lo en este contracto contenido, e cada casa e parte de ello assý commo sy por su sentençia o sentençias diffinitivas a nuestro pedimiento dadas e 
emologadas, consentidas e approbadas e passadas en cosa juzgada lo oviessen mandado, juzgado, determinado e sentençiado proçediendo contra nós e cada uno de nços los rebelles e contradictores e negligentes por toda censura eclesiástica e por todos los otros remedios del derecho e contra nuestros successores en las dichas capellanías e entrando e entregando en las dichas casas e en todos los otros bienes e rentas de la dicha nuestra mesa e vendiendo dellos a buen barato o a malo syn ser llamados nin oýdos e syn guardar orden de subastaçión alguna min otra solemnidat de derecho e fazer entrega e execuçión assí por las penas e multas deste contracto sy en ellas cayéremos commo por lo prinçipal e en este contracto contenido.

Para lo qual todo, expressamente obligamos lo suso obligado e renunçiamos e partimos de nós todas leyes e derechos canónicos e çeviles e todas constituciones papales, legaçiales, provinçiales, signodales, todos auxilios e remedios ordinarios, extraordinarios, todas excepciones, deffensiones, captelas e buenas razones de fecho e de derecho, todos privilegios e exemciones, e la ley que diz que "general renunçiaçión non vala», certificados de todọs auxilios e derechos en esta carta pertenescientes renunciar en contrario dello que nos non vala nin nos sea oýdo nin resçebido en alguna manera en juyzio nin fuera dél.

E porque esto sea firme, valedero e perpetuo para siempre, según suso dicho es, e non venga en dubda, Nós, los dichos lohan Alfonso, canónigo, e capellanes suso nombrados, por nós e en nombre de los otros capellanes absentes nuestros compañeros e que después de nós vinieren, rogamos a los presentes señores benefiçiados en la dicha eglesia cathedral de Çamora suso nombrados que sean de todo esto testigos.

E assý mesmo rogamos e pedimos a vós, Martýn Fernández de Bonilla, notario público por la abtoridat apostolical, que estades presente, que dedes desto todo a una de nós las dichas partes un instrumento o dos o más, quantos vos pidiéremos e entendiéremos que nos cumplen, signados de vuestro signo para guarda de nuestro derecho.

Testigos rogados que a esto fueron presentes: todos los dichos señores benefiçiados suso en el comienço deste instrumento nombrados.

Fecho e otorgado fue este contracto en el dicho cabilldo, día e mes e año suso dichos. 
E yo, el dicho Martýn Fernández de Bonilla, notario público por la abtoridat apostolical suso dicho, en uno con los dichos testigos presente fuy a todo lo suso dicho e en este público instrumento contenido.

E por mandado del dicho señor obispo e a ruego e pedimiento del dicho Juan Alfonso, canónigo, e de los dichos capellanes suso nombrados, seyendo ocupado, por otro fielmente lo fize escrivir segund que por mí pasó. El qual va escripto en çinco fojas de pergamino con esta en que va mi signo, todo junto en un quaderno; e va en fin de cada plana señalado de firma.

Por ende puse aquí este mi signo atal en testimonio de verdat, rogado e requerido. 
DOCUMENTO 2

\section{ESTATUTO DEL CAPELLÁN MAYOR DE LA IGLESIA DE ÁVILA}

In nomine Domini. Amen.

Manifiesto sea a todos cómmo en la iglesia cathedral de la noble çibdat de Ávila, viernes, doss días del mes de agosto, año del nascimiento de nuestro señor Ihesu Christo de mill e quinientos y quatro años, estando en la capilla de Sant Bernabé, que es dentro de la dicha iglesia, ayuntados en capítulo, llamados por su perteguero e tañida la campana segund que lo han de uso e de costumbre, el mui reverendo e mui magnífico señor don Alonso Carrillo de Albornoz, por la gracia de Dios e de la sancta iglesia de Roma obispo de la dicha iglesia de Avila, del consejo del rey y reyna nuestros señores, e los reverendos señores deán y cabildo de la dicha iglesia, todos juntamente de una concordia, nemine discrepante, en presençia de mí García González de Avila, notario público por las autoridades apostólica e obispal e notario capitular de los dichos señores deán y cabildo e de los testigos de yuso scriptos, establescieron e ordenaron e fizieron leer e publicar por mí, el dicho notario, el estatuto siguiente:

Por esperiençia nos consta e avemos sabido quán mal se ha conplido e cunple e servido e sirve el ofiçio y cargo que incunbe a fazer y dezir al capellán mayor desta nuestra uglesia de Avila, segund los statutos e antigua costumbre della que son los siquientes:

- que en acabando de tañer esté en el coro e comiençen todas las oras ansí matines como prima, tercia, sesta, nona, bísperas e completas e oras de nuestra señora e de finados, quando los oviere. 
- E diga las Capítulas e oraçiones e tome la capa e eche las fiestas e los perdones e bendiciones.

- E eche el agua bendita en el coro los domingos e pascuas so pena de un maravedí viejo.

- E que diga o faga dezir la missa del alva cantada en amanesçiendo so pena de un real.

- E que vaya a ençensar el alto mayor todos los días e fiestas que se acostumbren a ençensar, so pena de un maravedí viejo.

- E que mire por el Corpus Christi e lo aya de renovar e renueve de quinze en quinze días.

- E que aya de administrar los sanctos sacramentos a los feligreses e parrochianos e beneficiados e sus familiares de la dicha iglesia e a otras personas qualesquier.

- E que aya de yr e vaya con los capellanes de dicha iglesia por cualquier cuerpo que se enterrare en la dicha iglesia aunque no vayan beneffiçiados, o dar quien vaya por él, so pena de diez maravedís viejos.

E a esto ha dado e da mucha occasión e causa la pequeña pena que por los dichos statutos antiguos está puesta contra el tal capellán mayor por las faltas en que cayere, la qual aunque al tiempo que se impuso podía ser condina e bastante porque en aquel tienpo la dicha capellanía mayor se proveýa por el obispo e deán a cabildo e era ad nutum removible e por temor de no ser removido procurava de servirla bien en no fazer faltas; e porque a la sazón la dicha capellanía mayor valía e rentava poco e por el valor de la moneda vieja de que se pagava la pena, peroagora no es pena condigna ni bastante porque no se provee por el obispo e cabildo ni es ad nutum removible e porque vale e renta mucho más que entonçes, e por el poco valor de la moneda corriente en que se paga la dicha pena, por ende, queriendo proveer e remediar a lo presente e venidero de manera que lo que el tal capellán mayor no fiziere por serviçio de Dios lo aya de fazer e faga por temor de la pena temporal. 
Statuimos y ordenamos que el capellán mayor que agora es e fuere de aquí adelante o su lugar theniente sea tenudo e obligado a todos los dichos cargos segund que lo hera por virtud de los dichos statutos e antigua costunbre, e que si no viniere en acabando de tañer a començar los matines que caya en pena de veynte maravedís de la moneda corriente; e si los començare en tiempo e no estoviere a dezir la capítula e oración, que caya en la misma pena; e si en acabando de tañer no viniere a començar ñças ptras pras, es a saber: prima, tercia, sesta, nona, bísperas e completas e oras de nuestra Señora e de finados, quando las oviere, e non tomare la capa a las bísperas para yr sobre las sepulturas e dezir los responsos e non echare el agua bendita en el coro los domingos e pascuas e no echare las fiestas e perdones, que caya en pena por cada ora e por cada vegada que fiziere falta, de diez maravedís de la moneda corriente; e en esta mesma pena incurra si començare la ora e no dixere la capítula e oración, e si no dixere por si o por otro la missa del alva cantada, caya en pena por cada vez de doss reales de plata. E si la dixere, pero no al tienpo que es obligado, que es al alva en amanesciendo, que caya en pena de un real; e si non fuere a ençensar o no renovare el Corpus Christi fr ocho o ocho días e no fuere administrar los sacramentos o non fuere con los capellanes por el cuerpo o non diere quien vaya por él, que por cada cosa destas e por cada vez caya en pena de un real.

E que el serviçio del coro e el ençensar del altar e yr por el cuerpo con los capellanes no lo pueda fazer por otro salvo estando absente de la çibdat o enfermo o teniendo otro justo enpedimento, e entonces, pedida e avida licençia del cabildo e dexando el cargo a otro beneffiçiado de la dicha iglesia, ydóneo y suffiçiente a vista del cabildo, pero que a los matines pueda servir por otro beneffiçiado de la dicha iglesia aunque esté en la çibdat e no enfermo ni enpedido.

E porque podría acaesçer que fuese proveído de la dicha capellanía mayor alguna persona que non fuese ydónea e sufficiente para conplir e fazer los dichos cargos, por defecto de orden o de letras o de canto o de otro qualquier deffecto que al tal, el deán e cabildo lo pueda señalar e señalen tiempo e término convenible dentro del qual se aya de ordenar e fazerse ydóneo e sufficiente. $E$ si dentro del término a él asignado ansy non lo fiziere ni cumpliere, que dende en adelante no gane en la dicha iglesia ni le cuenten en la dicha capellanía.

E que el cabildo a costa del capellán mayor pueda poner e pongan otra persona, beneffiçiado de la yglesia, ydóneo e sufficiente, que supla e faga por él los dichos cargos. 
E porque el dicho capellán mayor pueda mejor servir e fazer su offiçio, que no le puedan echar ni echen semanas de missa ni de diácono ni subdiácono ni le puedan echar cantorias ni pueda dezir por otro missa ni diácono ni subdiácono.

E por mayor firmeza juramos a las órdenes que reçebimos de lo ansí guardar e fazer guardar e desde agora suplicamos al nuestro mui santo padre que aprueve e confirme este nuestro statuto e supla qualesquier defectos e solempnidades de fecho e de derecho que en él aya e pueda aver.

Testigos que a esto fueron presentes Juan Alvarez de Sanctiago e Vicente de Villalva, capellanes en la dicha iglesia de Avila, vezinos de Avila.

E después desto, en la dicha capilla de Sant Bernabé, este dicho día incontinenti, doss días del dicho mes de agosto del dicho año, estando presentes los dichos reverendos señores deán y cabildo de la dicha iglesia en presençia de mí, el dicho notario, e de los testigo de yuso scriptos, paresçio ý presente el bachiller Françisco de Quemada, capellán mayor en la dicha yglesia de Avila, e fuéle leýdo el dicho statuto de suso contenido de verbo ad verbum e fuéle dicho e notificado cómmo oy dicho día se avía fecho e otorgado porque ansí convenía al serviçio de Dios e de la dicha iglesia; e ansí leýdo, dixo que él como tal capellán mayor a quien prinçipalmente tocava el dicho statuto e lo en él contenido, consentía e consintió en él porque le pareçía ser justo e honesto e razonable; e que jurava e juró a Dios a Sancta María e a la señal de la cruz + en que puso su mano derecha, e a las palabras de los santos evangelios do quier que están escriptos, segund forma de derecho, de tener e guardar e conplir e obtemperar el dicho statuto e los otros statutos de la dicha iglesia según e por la vía e forma que en los dichos statutos e en cada uno dellos se contenía e de non pedir absoluçión ny relaxaçión ni dispensaçión ni conmutaçión desde dicho juramento nin de perjuro dél, si en el cayese e incurriesse, a nuestros señores el Papa nin a sus cardenales nin penitençiarios nin a arçobispos nin a obispos nin a sus provissores e vicarios nin a otra persona alguna. $E$ caso que le sea dado e conçesso de su proprio motu o en otra manera qualquiera, dél non usar nin se aprovechar.

E respondió al dicho juramenteo e dixo: Sí, juro, e Amén. 
E dio poder complido a todas las justiçias eclesiásticas que se lo fiziesen así tener e guardar e complir segund dicho es.

Testigos que a esto fueron presentes: Alcaraz, criado del dicho señor liçençiado, Pedro de Frías, provisor e Pedro de Morales, perteguero vezinos de Avila.

E después desto, en la dicha capilla de Sant Bernabé, luego encontinenti, este dicho día e mes e año suso dichos, estando presentes los dichos señores deán e cabildo en presençia de mí, el dicho notario, e de los testigos de yuso scriptos, luego el dicho Francisco de Quemada, capellán mayor en la dicha iglesia de Avila, dixo que por quanto en la provisión que le fue fecha de la dicha su capellanía mayor de la dicha iglesia de Avila la nonbrava e dezía ser dignidat e la verdat era que no era dignidat ni nunca lo fue salvo raçión, e fue nombrada dignidat por herror, por ende que declarava e declaró e que confessava e confesó que no era dignidat e renunçiava e renunció la dicha cláusula en su bulla contenida pues era commo es capellanía mayor e raçión en la dicha iglesia e non dignidat. Testigos los dichos.

E después desto, en la iglesia del señor Sant Viçente de Avila, tress días del dicho mes de agosto del dicho año, en presençia de mí el dicho notario público e de los testigos de yuso scriptos, estando presente el venerable señor Alonso Velázquez Serrano, canónigo en la dicha iglesia de Avila commo deputado para lo infrascripto por los dichos señores deán y cabildo, el dicho Francisco de Quemada, capellán mayor en la dicha iglesia de Avila, dixo que jurava e juró a Dios e a Sancta María e a la señal de la cruz + en que puso su mano derecha que estavan escriptas en un libro evangelisterio e al sancto sepulcro de San Vicente en que corporalmente puso su mano derecha e a las palabras de los sanctos evangelios do quier que son escriptas segund forma de derecho de terier e guardar e complir e observar el dicho statuto que de suso va encorporado que ansí leyó el dicho Francisco de Quemada, capellán mayor, de verbo ad verbum a cada una cossa e parte dél e todos los otros statutos de la dicha iglesia de Avila e los secretos del dicho cabildo; e si algund dampno viniere al dicho cabildo to ?

E si lo ansí fiziese que Dios le ayudase e valiese, e sy no qie El ge lo demandase mal e caramente en este mundo al cuerpo e en el otro al ánima ansý commo aquel que a sabiendas se perjura en el su sancto nonbre en vano; e demás que señor San Viçente e sus hermanas fuesen 
rogadores a nuestro señor de mostrar $m$,iraglo sobre él commo aquel que se perjura en el sancto nonbre en vano commo ha mostrado por otros, e respondió al dicho juramento e dixo: Sí, juro e Amen.

Testigos que a esto fueron presentes: Gil López, cura de la dicha iglesia de Sant Vicente e Diego Gómez Armenteros, beneffiçiado en la dicha iglesia de Sant Viçente e Juan De Lavajos, capellán de la dicha iglesia de Sant Viçente, vezinos de Avila.

Por que yo, Garci González de Avila, notario público por las auctoridades apostolica e obispal e notario capitular de los dichos reverendos señores deán e cabildo de la yglesia de Avila, fuy presente a todo lo que dicho es e cada una cosa e parte dello en uno con los dichos testigos, e este instrumento fiz scrivir para los dichos señores deán e cabildo a instançia e otorgamiento de dicho capellán mayor. E lo signé deste mi acostumbrado signo atal en testimonio de verdad. Rogado e requerido. Garssias González, notario apostolical. 